\title{
Aging-Dependent and -Independent Modulation of Associative Learning Behavior by Insulin/Insulin-Like Growth Factor-1 Signal in Caenorhabditis elegans
}

\author{
Hana Murakami, ${ }^{1,2}$ Karalee Bessinger, ${ }^{1}$ Jason Hellmann, ${ }^{1}$ and Shin Murakami ${ }^{1,2}$ \\ ${ }^{1}$ Gheens Center on Aging, Department of Biochemistry and Molecular Biology, University of Louisville School of Medicine, Louisville, Kentucky 40202, and \\ ${ }^{2}$ Department of Dermatology and Pathology, Geriatrics Center and Institute of Gerontology, University of Michigan Medical School, Ann Arbor, Michigan \\ 48109
}

\begin{abstract}
Mutations in the insulin/IGF-1 neuroendocrine pathway extend lifespan and affect development, metabolism, and other biological processes in Caenorhabditis elegans and in other species. In addition, they may play a role in learning and memory. Investigation of the insulin/IGF-1 pathway may provide clues for the prevention of age-related declines in cognitive functions. Here, we examined the effects of the life-extending (Age) mutations, such as the age-1 (phosphatidylinositol3-0H kinase) and daf-2 (insulin/IGF-1 receptor) mutations, on associative learning behavior called isothermal tracking. This thermotaxis learning behavior associates paired stimuli, temperature, and food. The age-1 mutation delayed the age-related decline of isothermal tracking, resulting in a $210 \%$ extension of the period that ensures it. The effect is dramatic compared with the extension of other physiological health spans. In addition, young adults of various Age mutants (age-1, daf-2, clk-1, and eat-2) showed increased consistency of temperature-food association, which may be caused by a common feature of the mutants, such as the secondary effects of life extension (i.e., enhanced maintenance of neural mechanisms). The age- 1 and daf- 2 mutants but not the other Age mutants showed an increase in temperature-starvation association through a different mechanism. Increased temperature-food association of the daf-2 mutant was dependent on neuronal Ca ${ }^{2+}$-sensor $n c s-1$, which modulates isothermal tracking in the AIY interneuron. Interestingly, mutations in the daf-7 TGF $\beta$ gene, which functions in parallel to the insulin/IGF-1 pathway, caused deficits in acquisition of temperature-food and temperature-starvation association. This study highlights roles of the Age mutations in modulation of certain behavioral plasticity.
\end{abstract}

Key words: aging; life extension; insulin/IGF-1 signal; stress resistance; learning and memory; behavioral plasticity

\section{Introduction}

Learning and memory ensure appropriate behavioral responses to new or existing environments in a variety of animal species. Caenorhabditis elegans learns clues for food (primarily bacteria), such as the temperature at which they encounter bacteria. Isothermal tracking is an experience-dependent behavior, in which animals learn to associate paired stimuli, temperature (conditioned stimulus), and food (unconditioned stimulus) (Mori, 1999). By taking advantage of this associative learning behavior, worms can be trained to move toward a temperature and trace it. Optimal isothermal tracking requires the neuronal $\mathrm{Ca}^{2+}$. dependent ncs-1 gene, which encodes a member of the wellconserved EF-hand calcium binding proteins (Gomez et al., 2001). Expression of the $\mathrm{Ca}^{2+}$-dependent $n c s-1$ gene in the AIY

Received Sept. 1, 2004; revised 0ct. 5, 2005; accepted 0ct. 5, 2005

This work was supported by a startup fund from the Department of Dermatology, University of Michigan Medical School, by the National Institute on Aging, and by the Gheens Foundation. We thank Abby G. Johnson for technical assistance, the Caenorhabditis Genetics Center for some strains, and Drs. Makoto Koga, Yasumi Oshima, Cathy Wolkow, Oliver Hobert, and Gary Ruvkun for some plasmid and strains.

Correspondence should be addressed to Shin Murakami, 580 South Preston Street, Baxter II, Room 102, Louisville, KY 40202. E-mail: shin.murakami@louisville.edu.

D0I:10.1523/JNEUROSCI.3600-04.2005

Copyright $\odot 2005$ Society for Neuroscience $\quad$ 0270-6474/05/2510894-11\$15.00/0 interneuron is essential for isothermal tracking (Gomez et al., 2001). AIY and the interneuron AIZ mediate thermal inputs from thermosensory neurons.

Previous studies show that the insulin/IGF-1 pathway specifies lifespan and stress resistance as well as a variety of biological processes in C. elegans. The pathway involves daf-2 (insulin/ IGF-1 receptor gene), age-1 (phosphatidylinositol 3-OH kinase gene), and other components, negatively regulating daf-16 (forkhead transcription factor gene) (Kenyon et al., 1993; Larsen et al., 1995; Murakami and Johnson, 1996; Lin et al., 1997; Ogg et al., 1997), old-1 (transmembrane tyrosine kinase gene) (Murakami and Johnson, 2001), and numbers of other genes (Honda and Honda, 1999; McElwee et al., 2003; Murphy et al., 2003; Ookuma et al., 2003). Mutations in age-1 and daf- 2 confer life extension and resistance to multiple forms of stress, including oxidative stress (Larsen, 1993; Vanfleteren, 1993), heat (Lithgow et al., 1995), UV radiation (Murakami and Johnson, 1996), and heavy metals (Barsyte et al., 2001). Similarly, heterozygous knock-out mice of IGF-1 receptor (igf-1 $r^{+/-}$) and embryonic fibroblasts from the $i g f-1 r^{+/-}$mice are resistant to oxidative stress (Holzenberger et al., 2003), whereas low levels of growth hormone/IGF-1 and other hormones cause epigenetic changes in skin fibroblasts, leading to resistance to multiple forms of stress (Murakami et al., 
2003). The insulin/IGF-1 pathway in the nervous system specifies lifespan (Wolkow et al., 2000) but may play a relatively minor role in lifespan determination (Libina et al., 2003). In parallel to the pathway, the $d a f-7$ TGF $\beta$ neuroendocrine pathway regulates metabolic and feeding-related biological processes. The daf-7 phenotypes include formation of an alternative larval stage (dauer), metabolic shift to fat accumulation, and reproduction (Riddle and Alberts, 1997). The TGF $\beta$ signal does not modulate increased longevity (Kenyon et al., 1993; Larsen et al., 1995) and resistance to multiple forms of stress (Murakami and Johnson, 1996; Riddle and Alberts, 1997).

Alterations in insulin/IGF-1 signal are tightly associated with impaired nervous function in age-related neurodegenerative diseases (Wickelgren, 1998). We investigated whether the age-1 and daf-2 mutations in the insulin/IGF-1 pathway affect the thermotaxis learning paradigm. The insulin/IGF-1 pathway mutants are more adept at this form of associative learning than the wild-type animals are. Our results suggest that the life-extending mutants ensure certain enhancements in learning behavior, which may contribute to the quality of life in C. elegans.

\section{Materials and Methods}

Strains and media. All strains were maintained in a nematode growth (NGM) agar medium spotted with Escherichia coli, OP50, as a food source as described previously (Murakami and Johnson, 1996, 2001). The wild-type strain, N2, was obtained from the Caenorhabditis Genetics Center. Mutant strains used were as follows: age-1 (hx546), daf-2(e1368), daf-2(e1370), daf-7(e1372), daf-7(m62), daf-16(m26), daf-16(m27), and $n c s-1$ (qa406). Mutations (affected domain) are as follows: S573L (ligandbinding domain) in daf-2(e1368); P1465S (kinase domain) in daf2(e1370); P271S (ligand domain) in daf-7(e1372); Q246-Stop (ligand domain) in daf-7(m62); G to A transition at the exon 2 splice donor (upstream of the Forkhead domain) in daf-16(m26); GC to AC amber stop in exon 8 (forkhead domain) in daf-16( $\mathrm{m} 27)$; deletion of exons 1-5 in $n c s-1$ (qa406); and not identified in age-1(hx546) (Ren et al., 1996; Kimura et al.,1997; Lin et al., 1997; Ogg et al., 1997; Gomez et al., 2001). Chromosomal arrays used were as follows: $p$ (daf-7), ks31Ex[pK8ETBdaf7c, pK8I1-gfpE, KS+]; p(daf-16), mkEx10[p(daf-16), punc25p::GFP]; $p(t t x-3::$ age-1), mkEx11[p(ttx-3::age-1), punc25p::GFP]; p(ttx-3::daf-7), $m k E x 14$ [p(ttx-3::daf-7), punc25p::GFP]; and the three chromosomal arrays, $p$ (unc-14p::age-1), p(ric-19p::age-1), and p(mec-7::age-1) (formal names of the chromosomal arrays to be assigned by Dr. C. Wolkow, National Institute on Aging, Bethesda, MD). Double mutants, age-1; daf-16 and daf-2; daf-16 were constructed and maintained as described previously (Murakami and Johnson, 1996). daf-2; ncs-1 was generated by genetic cross and was confirmed by backcrossing with the wild type. A $p$ (daf-7) transgenic strain expressing the daf-7 TGF $\beta$ gene (Koga et al., 1999) was a kind gift from Drs. Y. Oshima and M. Koga (Kyushyu University, Fukuoka, Japan). The daf-7(e1372); p(daf-7) transgenics were created by crossing the $p$ (daf-7) transgenics with the daf-7(e1372) strain, followed by isolating $\mathrm{F} 2$ progenies. The daf-7 background was confirmed by backcross with $\mathrm{N} 2$. The age-1 cDNA and strains carrying $p$ (unc-14p::age-1), p(ric-19p::age-1), or p(mec-7::age-1) are generous gifts from Drs. G. Ruvkun (Massachusetts General Hospital, Boston, MA) and Wolkow (National Institute on Aging) (Wolkow et al., 2000). The plasmid $p(t t x 3 p::$ age -1$)$ was constructed using the $t+x 3$ promoter plasmid from Dr. O. Hobert (Columbia University, New York, NY) (Hobert et al., 1997) and microinjected as described previously (Murakami and Johnson, 1996, 2001). Some strains were obtained from the Caenorhabditis Genetics Center.

Growth conditions. For conditioning at $15^{\circ} \mathrm{C}$, worms were grown at $25^{\circ} \mathrm{C}$ (referred to as " $25^{\circ} \mathrm{C}$ condition") on NGM agar plates seeded with Escherichia coli, OP50, except for the following strains. For daf-2, daf-7, and their controls, we used the shift-up condition from 15 to $25^{\circ} \mathrm{C}$ (referred to as "shift-up condition"). Eggs were incubated for $1-2 \mathrm{~d}$ at $15^{\circ} \mathrm{C}$ to avoid constitutive dauer formation, and L2/L3 larvae were subsequently shifted up and grown at $25^{\circ} \mathrm{C}$ as described previously (Murakami and Johnson, 1996, 2001). For conditioning at $22^{\circ} \mathrm{C}$, all of the worms were grown at $17^{\circ} \mathrm{C}$. To obtain developmentally synchronized population, $\mathrm{L} 4$ animals were picked and incubated for $24 \mathrm{~h}$ at either $25^{\circ} \mathrm{C}$ (for $15^{\circ} \mathrm{C}$ conditioning) or $17^{\circ} \mathrm{C}$ (for $22^{\circ} \mathrm{C}$ conditioning) to let them grow up into adults. The worms grown at $17^{\circ} \mathrm{C}$ for $24 \mathrm{~h}$ were likely developmentally younger than the worms grown at $25^{\circ} \mathrm{C}$ for $24 \mathrm{~h}$; any possible developmental difference was controlled by ensuring that all young-adult worms had begun egg laying. The resulted adults or otherwise specified were conditioned and used for learning assays. We define the adults that are grown for $24 \mathrm{~h}$ after L4 larval stage as "young adults" (day 1 adults; egg laying has begun). Under the shift-up growth condition, the daf-2 and daf-7 mutants still show phenotypes, including metabolic shift to fat accumulation and feeding behaviors; the daf-2 mutant also shows lifeextension phenotypes (Murakami and Johnson, 1996).

Assessment of isothermal tracking, survivorship, and motor activities. Isothermal tracking was determined in a single-animal assay as described previously (Murakami and Murakami, 2005). Approximately 20 adults were incubated at $15 \pm 0.5^{\circ} \mathrm{C}$ with food to learn the temperature for $18 \mathrm{~h}$. Each adult was first placed on an NGM agar plate for a few minutes (typically $2 \mathrm{~min}$ ) and then transferred to a radial thermal gradient on a $100 \mathrm{~mm}$ NGM agar plate for $90 \mathrm{~min}$. The fraction showing isothermal tracking was determined by the worm trace left on the plate. Note that the thermal gradient does not cover the growth temperature, $25^{\circ} \mathrm{C}$, and, thus, untrained worms cannot track the growth temperature. For thermotaxis population assay, a cohort of $\sim 15$ adults was conditioned with food as described above (well-fed animals). Another cohort of animals was conditioned and then was starved at $15^{\circ} \mathrm{C}$ for $2.5 \mathrm{~h}$ on an NGM agar plate (starved animals); for $22^{\circ} \mathrm{C}$-starvation conditioning, animals were starved for $1.0 \mathrm{~h}$. It is worth noting that starvation at a temperature triggers temperature avoidance, but, when starvation is prolonged, it abolishes the avoidance behavior. Well-fed and starved animals were placed on a plate for $60 \mathrm{~min}$ in a thermal gradient (typical minimum and maximum temperatures were 8 and $24^{\circ} \mathrm{C}$, respectively), and the animals in each temperature area were counted. To minimize environmental factors that affect isothermal tracking, all of the experiments were performed in a consistent environment (room temperature range was 22$24^{\circ} \mathrm{C}$ and humidity was $\sim 50 \%$ ). All of the assays were replicated more than three times including at least one blind test. To assess isothermal tracking during aging, initially $200-300$ adults grown at $25^{\circ} \mathrm{C}$ were used, and 15-20 adults were tested at each age. In parallel, $\sim 50$ worms were tested for survival. Worms were transferred to new NGM plates with food everyday during the reproduction period and then transferred every 2-3 d until all worms were dead. Death was determined by mechanical stimuli.

Each experiment was replicated three times or more. Paired Student's $t$ test was performed to calculate probability. The results were shown as mean \pm SD or SEM. Statistical analysis was performed by NCSS statistical software (NCSS, Kaysville, UT) using $t$ test, log rank test, or ANOVA post hoc analysis (Newman-Keuls test).

Locomotion assays. Well-fed and starved adults were used for assessing body bends in $30 \mathrm{~s}$ intervals with or without bacteria. Animals were washed twice in S-basal media. Body bends were measured 2 min after being placed on an NGM agar plate. Each adult was subsequently transferred onto bacteria, and, after $2 \mathrm{~min}$, body bends were measured. For starvation, adults were washed twice in S-basal media and starved for 30 min on an NGM agar plate. Body bends were assessed as described above. Locomotion was also determined by motor activity. The adult worms were gently tapped at the back of the worms by a 32 gauge platinum wire; the stimulus was sufficient to induce their response but did not cause any degeneration on the tapped region. The fraction of the animals that moved $>1 \mathrm{~mm}$ (equal to the length of a single worm) after the mechanical stimuli were scored. Moving speed and rate of mobility were determined by using young-adult hermaphrodites (day 1 animals after L4 larvae; see above, Growth conditions). After being placed on an NGM agar plate for $\sim 2 \mathrm{~min}$, each adult was transferred to a new NGM plate. The distance that each adult moved in $10 \mathrm{~s}$ was measured. The rate of mobility and the locomotion speed were measured independent of thermotaxis assays. Basic movements of animals in a $30 \mathrm{~s}$ interval were also measured: forward sinusoidal movement (forward turns), reversal movement (backward turns), and the turns in which animals change 
direction (Omega/U turns); in Omega turns, an animal's head touches the tail and thus the shape of the animal looks similar to the shape of the Greek letter Omega whereas, in U turns, the angle of the body bend is typically $>90^{\circ}$. At least a blind test was included for each assay.

Assessment of humidity effect on isothermal tracking. Young adults were trained at the humidity of $50 \%$ for $18 \mathrm{~h}$, and then they were placed in a thermal gradient created on $9 \mathrm{~mm}$ NGM agar plates that had been preincubated for $15 \mathrm{~min}$ at the humidity of 30,50 , or $100 \%$ monitored by a hygrometer. Under either humidity, isothermal tracking was assessed for 90 min. Humidity at 30 and 100 was achieved by using dehumidifying compound (MaryKate, Warminster, PA) or a humidifier placed in the incubator. Alternatively, $100 \%$ of humidity was also achieved using a sealed container with wet paper towels.

Chemotaxis assays. Chemotaxis and chemotaxis adaptation assays were performed as described previously (Troemel et al., 1997) with some modifications (Nuttley et al., 2002). Well-fed animals were assessed on $100 \mathrm{~mm}$ assay plates, containing $9 \mathrm{ml}$ of $1.8 \%$ agar and $10 \mathrm{~mm}$ MOPS [3-(N-morpholino)propanesulfonic acid], $\mathrm{pH}$ 7.2. For chemosensory conditioning, we used the standard method: $2 \mu \mathrm{l}$ of $100 \%$ benzaldehyde was placed on the inner side of the plate lids, and animals were exposed to benzaldehyde on NGM plates with or without food for the time indicated. Fifteen minutes before the assay, we added $1 \mu \mathrm{l}$ of sodium azide on one spot on the edge of the plate and another spot on the other side of the plate. Then, $1 \mu \mathrm{l}$ of $1 \%(\mathrm{v} / \mathrm{v})$ benzaldehyde was added to one of the spots, and $1 \mu \mathrm{l}$ of ethanol (control diluent) was added to the other spot. Animals were washed twice with S-basal medium $(0.1 \mathrm{M} \mathrm{NaCl}, 0.05 \mathrm{M}$ potassium phosphate, $\mathrm{pH} 6.0$, and $5 \mathrm{mg} / \mathrm{L}$ cholesterol) and once with water and then placed in the center of the assay plate. We counted the number of the animals in the odorant area (area A; $30 \mathrm{~mm}$ in diameter from the odorant spot) and in the control area (area C; $30 \mathrm{~mm}$ in diameter from the control spot) after $1 \mathrm{~h}$; the remaining area is designated area B. A chemotaxis index $(\mathrm{CI})$ was calculated using the following formula: attraction (or avoidance) index $=(A-C) / N$, where $N$ is the total number of animals.

RNA interference. daf-2(RNAi) were performed by feeding the RNA interference (RNAi) bacteria carrying the daf-2(RNAi) vector on an NGM plate supplemented with carbenicilin as described previously (Fraser et al., 2000; Timmons et al., 2001, 2003; Dillin et al., 2002). The daf-2(RNAi) bacteria were cultured overnight at $37^{\circ} \mathrm{C}$ and spotted on the NGM plates with $25 \mu \mathrm{g} / \mathrm{ml}$ carbenicilin. RNA expression was induced by adding $100 \mu \mathrm{l}$ of IPTG (isopropyl- $\beta$-D-thiogalactopyranoside)/carbenicilin ( $0.1 \mathrm{M}$ IPTG and $25 \mu \mathrm{g} / \mathrm{ml}$ carbenicilin) onto the bacterial spot and incubated at room temperature for $2 \mathrm{~h}$. Animals (L3/L4 larvae) were fed and grown with RNAi bacteria, and then eggs from the RNAi fed animals were collected and placed in NGM plates seeded with each RNAi bacterial strain. RNAi animals were grown at $25^{\circ} \mathrm{C}$ until they are assessed for thermotaxis learning behavior. We used the $r r f-3$ mutant that allows efficient gene knock-out in the nervous system (Simmer et al., 2002).

\section{Results \\ Delay of age-related declines of isothermal tracking in the long-lived age-1 mutant}

Each animal was incubated at $15^{\circ} \mathrm{C}$ to learn the temperature with food and was then assessed for isothermal tracking (see Materials and Methods). The reference allele of age-1, $h \times 546$, was initially used, because age-1(hx546) is the least pleiotropic mutation among Age mutations (Johnson, 1990). We found that humidity affected isothermal tracking (see below) but not lifespan $[p=$ 0.50; mean \pm SEM lifespans were as follows: wild type at $50 \%$ humidity, $13.8 \pm 0.3 \mathrm{~d}(n=61)$; wild type at $100 \%$ humidity, $14.7 \pm 0.7 \mathrm{~d}(n=58)]$. Thus, all of the assays were performed under the consistent humidity of $\sim 50 \%$ (see Materials and Methods).

The age-1(hx546) animals performing isothermal tracking were significantly higher in number than the wild type during aging $(p<0.0001)$ (Fig. 1a). Because animals that cannot move should increase in number during aging and may affect the result, (a)

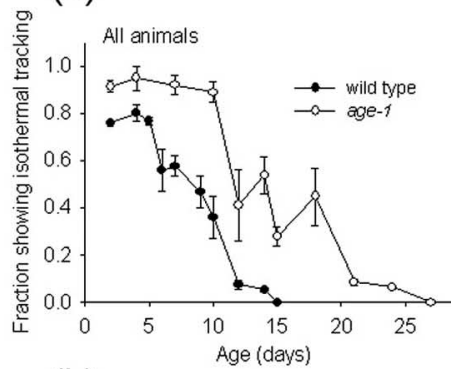

(b)

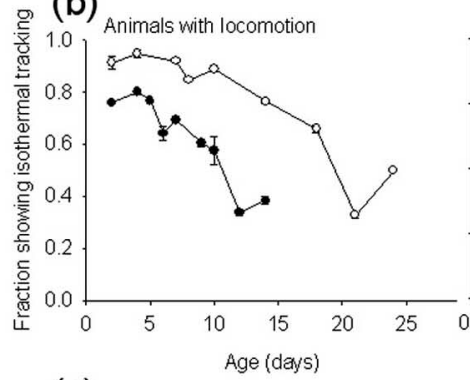

(c)

(d)

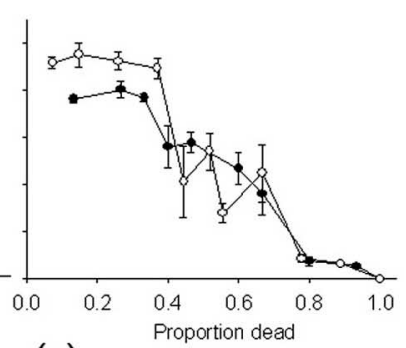

(e)

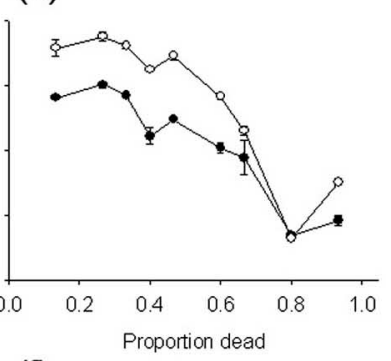

(f)

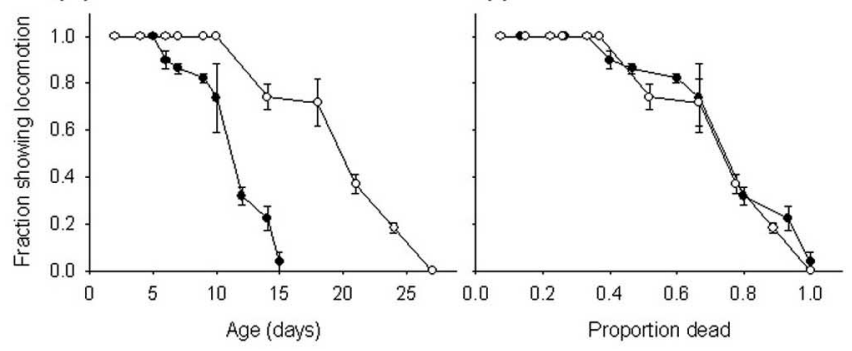

Figure 1. Aging of learning and motor activity. $\boldsymbol{a}$, Isothermal tracking of all of the animals during aging. $\boldsymbol{b}$, Isothermal tracking of animals showing locomotion during aging. The animals that did not show locomotion were excluded from $\boldsymbol{a}$. This is a more accurate indicator of learning behavior than $\boldsymbol{a}$. c, Fraction of adults performing locomotion (motor activity) during aging. The fractions shown in $\boldsymbol{a}-\boldsymbol{c}$ are also presented as a function of survivorship. $\boldsymbol{d}$, Isothermal tracking of all animals. $\boldsymbol{e}$, Isothermal tracking of animals that showed locomotion. $\boldsymbol{f}$, Locomotion. Isothermal tracking and locomotion were assessed in a single-animal assay (see Materials and Methods). Mean and SEM of three or more experiments are presented. Animals were grown at $25^{\circ} \mathrm{C}$.

we determined isothermal tracking among the animals that showed locomotion. The result shown in Figure $1 b$ confirmed that the age- 1 animals show high isothermal tracking during aging $(p<0.0001)$, suggesting that the age-1 mutation causes delay of age-related declines in isothermal tracking. The age-1 mutant also showed delayed age-related decline in locomotion compared with the wild type $(p<0.0001)$ (Fig. $1 c)$.

We compared isothermal tracking against survivorship (i.e., fraction of the animals surviving), an indicator of physiological aging (Pletcher et al., 2002). If the age-1 mutation simply delays physiological aging, isothermal tracking should be indistinguishable between the wild-type and the age-1 mutant at similar physiological age. The age-1 mutant showed a significant increase in isothermal tracking early in life $(0-40 \%$ of the proportion dead in Fig. $1 d)(p<0.0001)$ but not in mid or late life $(40-100 \%$ of the proportion dead in Fig. 1d) (see Fig. 4). In contrast, motor activities were similar in age-1 $(h \times 546)$ and the wild type during physiological aging (Fig. $1 f$ ) and in young adults (Fig. $1 c, f$ ). The results have two implications: (1) the age-1 mutant shows delays of age-related deterioration of isothermal tracking and locomotion; and (2) early in life, the age-1 mutant shows increased peak 


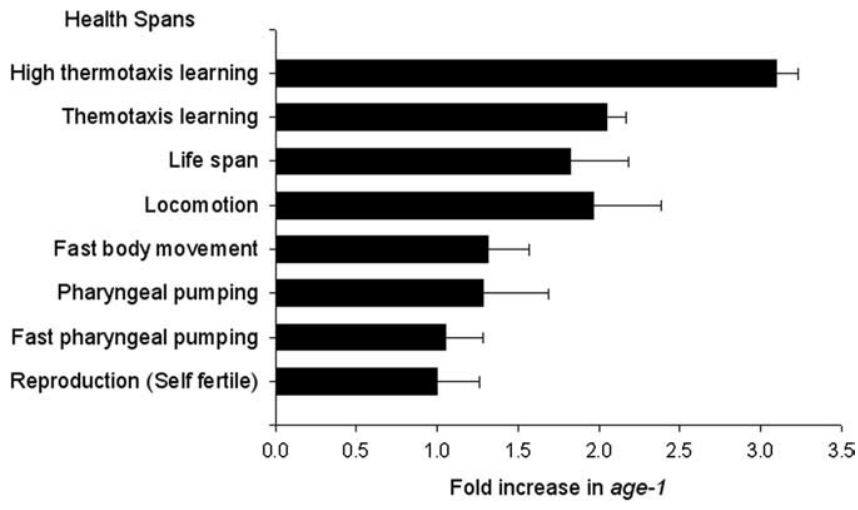

Figure 2. Extended health spans in the age-1 mutant. Several aspects of health span, which have differing degrees of increase in the age- 1 mutant over wild type, are shown. Fold increases were calculated by using the data from this study (high thermotaxis learning, thermotaxis learning, and locomotion spans), that by Murakami and Johnson (1996) (lifespan), and that by Huang et al. (2004) (the rest of the health spans). High thermotaxis learning represents the period with $>75 \%$ of the animals showing learning behavior. Animals were grown at $25^{\circ} \mathrm{C}$. (a)

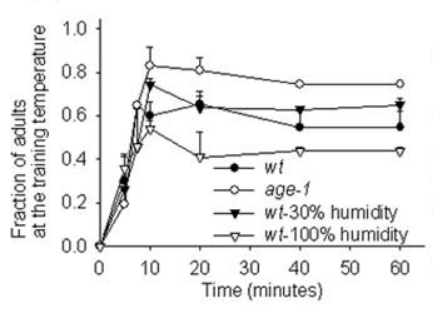

(b)

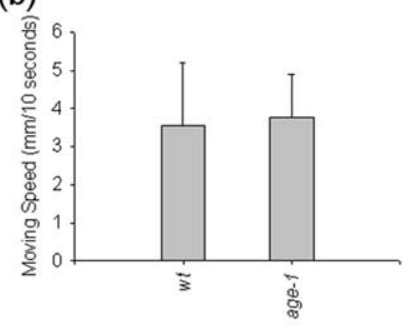

(c)

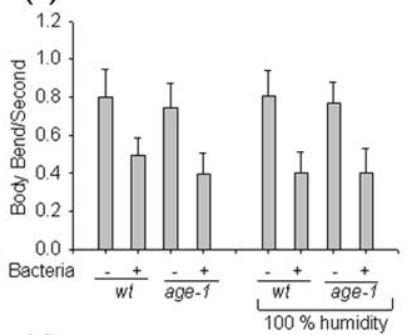

(d)

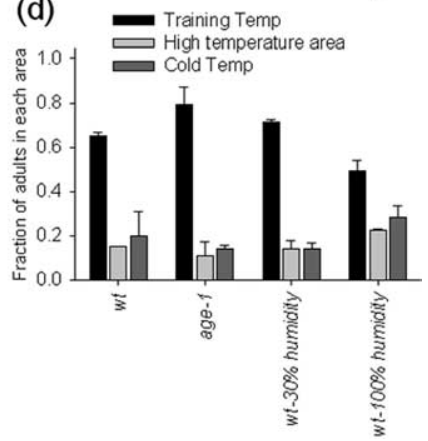

Figure 3. Thermotaxis and motor activity phenotypes in age-1. $\boldsymbol{a}$, Time course analysis of thermotaxis. Young adults were conditioned at the training temperature for $18 \mathrm{~h}$ and were placed in a thermal gradient. The age-1 $(h \times 546)$ mutant and the wild type (wt) were used. The adults in the training temperature area $\left(16 \pm 2{ }^{\circ} \mathrm{C}\right)$ were counted at each time point. Mean and SEM of the results from two experiments are shown. $\boldsymbol{b}$, Locomotion speed in the absence of food. $c$, Rate of mobility (rate of body bends) of well-fed animals in the presence or absence of food. Moving speed and the rate of mobility in the absence of food (Bacteria-) represent motor activities to look for food, such as those in the isothermal-tracking assay. In the absence of food, the moving speed and rate of mobility are similar in the wild type and in age-1 ( $\mathrm{h} \times 546)$ ( $p=$ 0.72 and 0.35 by $t$ test, respectively). The results under $100 \%$ of humidity were also shown. Bacteria + indicates the presence of food. $\boldsymbol{d}$, Normal thermophilicity and cryopilicity of age-1. After conditioning, animals were tested on a thermal gradient for $60 \mathrm{~min}$. We counted the number of animals at the trained temperature area $\left(14-18^{\circ} \mathrm{C}\right)$, high temperature area $\left(>18^{\circ} \mathrm{C}\right.$; typically $\left.18-24^{\circ} \mathrm{C}\right)$, and low temperature area $\left(<14^{\circ} \mathrm{C}\right)(n=39$ for age- $1 ; n=44$ for wild type). Similar results were also observed after $90 \mathrm{~min}$. Animals were grown at $25^{\circ} \mathrm{C}$.

consistency of association of paired temperature and food. Note that we used the terms "aging" and "age-related" to indicate "chronological aging" throughout the text unless otherwise noted.

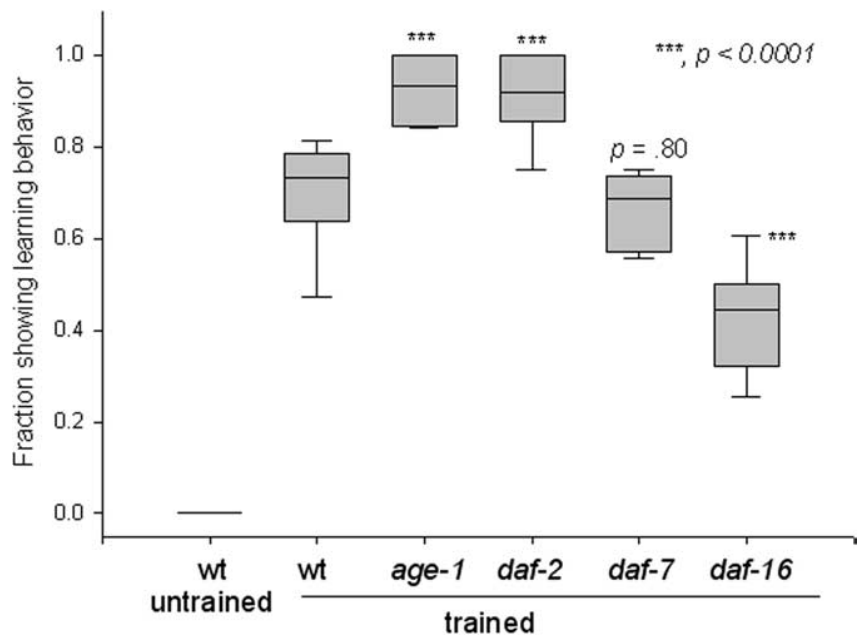

Figure 4. Increased isothermal tracking in the Age mutants but not in a daf-7TGF $\beta$ mutant. Learning activity of young adults in various mutants. The fraction of young adults ( $3-4 \mathrm{~d}$ old $)$ performing isothermal tracking is indicated. Each box plot represents the median (bar in gray box), 25-75 percentiles (gray box), and 10-90 percentiles (shorter bars). The animals were trained for $18 \mathrm{~h}$. All of the young animals showed normal locomotion here and in the following figures unless otherwise mentioned. All genotypes of the strains used were age-1 $(h \times 546)$ and daf-2(e1370) in the insulin/IGF-1 hormonal pathway and daf-7(e1372) in the TGF $\beta$ hormonal pathway. Values are presented as mean and SEM. The results of all of the animals throughout the manuscript were combined and shown. For examples of growth-temperature matched comparison, see Figure 7. wt, Wild type.

\section{Threefold extension of the period with a high thermotaxis learning behavior in the age-1 mutant}

Previous studies (Mori and Ohshima, 1995; Gomez et al., 2001) show that $\sim 75 \%$ of young animals show isothermal tracking (Fig. 2, High thermotaxis learning). We estimated the period with $>75 \%$ of animals showing isothermal tracking. Using Figure $1 a$, the period was $9.3 \pm 0.4 \mathrm{~d}$ in the age- 1 mutant, whereas it was $3.0 \pm 0.2 \mathrm{~d}$ in the wild type. Thus, the period showing high thermotaxis tracking in age- 1 is extended by $210 \%$ (Fig. 2 ). The extension is dramatic compared with the life extension shown by the age-1 mutant (65\% extension) (Johnson, 1990), the period that ensures locomotion ( $82 \%$ extension) and other physiological health spans, including reproduction period $(0.0 \%$ extension), fast body movement ( $31.7 \%$ extension), fast pharyngeal pumping span (4.9\% extension), and pharyngeal pumping span (28.8\% extension) (Huang et al., 2004).

\section{The age-1 mutation does not increase motor activity}

Isothermal tracking can be divided into three functions: perception of the two stimuli (temperature and food), association of the stimuli, and motor output. Because increased perception of the stimuli or increased motor activities may increase isothermal tracking, we performed detailed analysis of isothermal tracking in young adults (see Materials and Methods).

First, we investigated thermal perception by measuring the fraction of the young adults in the trained temperature area at various time points. The assay should assess how fast trained adults sense and move to the training temperature. In a typical assay, the age- 1 adults and the wild-type adults similarly moved to the temperature area during the first $10 \mathrm{~min}$ (Fig. $3 a, 0-10$ $\mathrm{min})$. After the first $10 \mathrm{~min}$, the age-1 adults showed higher preference to the temperature than the wild type. Thus, we did not observe any evidence for increased perception of stimuli. Accuracy of the temperature traced by the learned adults was $15 \pm$ $0.5^{\circ} \mathrm{C}$ and was similar between age- 1 and the wild type. Interest- 
ingly, high humidity reduced isothermal tracking (Fig. 3a,d). Second, there was no significant difference in locomotion speed (Fig. $3 b$ ). The rate of mobility in the presence of food represents the response to the food signal (Sawin et al., 2000) and was not significantly different in the well-fed and starved age- 1 animals ( $p=0.78$ ) (Fig. $3 c$ and data not shown). In addition, conditioned age- 1 animals show locomotion behaviors similar to the wild-type animals inside and outside of the training temperature (for well-fed, see Fig. 9a,b; for starved, data not shown). Third, the age-1 mutant did not show abnormalities in thermal perception, including thermophilicity and cryophilicity (Fig. $3 d$ ). Together, it is unlikely that the age-1 mutation increases motor activities. Thus, it is possible that the increased consistency of isothermal tracking in age- 1 is caused by an increased association of paired temperature and food stimuli; however, we cannot exclude the possibility that increased thermal perception also contributes to increased isothermal tracking.

\section{Consistency of thermotaxis learning behavior in young adults is increased in the Age mutants and is reduced in daf-16}

Similar to age-1, the long-lived daf-2(e1368) and daf-2(e1370) mutants showed significantly higher fraction of animals demonstrating isothermal tracking than the wild type $(p<0.0001$ in Fig. $4 ; p=0.005$ in Fig. 7). The daf-2 mutants showed an increase by $\sim 35 \%$ (Fig. 4 ). In contrast, the daf-16 mutants showed reduced isothermal tracking (Fig. 4 and the text below). When grown at $25^{\circ} \mathrm{C}$, daf- $16(\mathrm{~m} 26)$ showed $62 \%$ reduction $(p<0.0001)$ (Fig. 4), whereas daf-16(m27) showed $22 \%$ reduction $(0.55 \pm$ $0.06 ; n=87 ; p=0.02)$. Consistently, the reduced isotheral tracking in daf-16 (m26) was rescued by expression of daf-16 (Fig. $5 a$ ). The reduction became small or diminished when the mutant animals were grown at $15^{\circ} \mathrm{C}$ for $2 \mathrm{~d}$ and shifted up at $25^{\circ} \mathrm{C}$ (see Fig. $7 a$, Well fed). The result suggests that early development may be critical for levels of isothermal tracking. Mutations in the daf-16 gene showed short lifespan and dauer-defective phenotypes, which are the effects opposite to the age- 1 and daf- 2 mutations. Abnormal motor activity and perception of temperature and food in the mutants were not observed (data not shown). Thus, the reduction of the insulin/IGF-1 signal shows a correlation with increased association of stimuli, whereas activation of the signal was correlated with decreased association.

Increased isothermal tracking of the age- 1 and daf- 2 mutants was suppressed by daf-16(m26) (Fig. 5a, age-1; daf-16 and daf-2; daf-16). Untrained animals did not show isothermal tracking in the wild type or in the mutant strains described within (Fig. 4 and data not shown). These results indicate that the insulin/IGF-1 pathway modulates association of the paired stimuli in young adults.

\section{Increased isothermal tracking requires a function of} calcium-dependent $\boldsymbol{n c s}$ - 1

The $\mathrm{Ca}^{2+}$-dependent $n c s-1$ gene is required for optimal isothermal tracking (Gomez et al., 2001). The ncs-1 knock-out, ncs- (b) $* p<0.05$ $*, p<0.001$ ***, $p<0.0001$

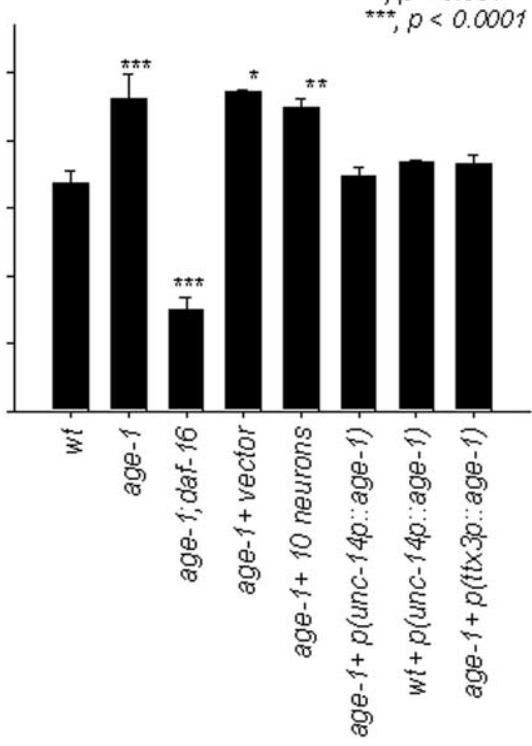

Figure 5. The effect of neuronal expression of age-1 CDNA and genetic analysis of isothermal tracking. $\boldsymbol{a}$, Isothermal tracking was assessed in the genetic background indicated in the figure. Animals were grown under the shift-up condition (see Materials

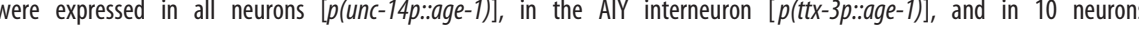
more than three experiments. wt, Wild type.

1(qa401), shows reduced isothermal tracking but shows normal chemotaxis, locomotion, and thermal-avoidance behaviors. In mammals, insulin/IGF-1 receptor is known to interact with calcium signaling through phospholipase C- $\gamma$ or other components (Scharenberg and Kinet, 1998; Lee et al., 2004). Thus, we reasoned that insulin/IGF-1 signal could have genetic interaction with $n c s-1$. If $n c s-1$ and insulin/IGF-1 signal function independently, the double mutant $n c s-1$; daf-2 should show an intermediate phenotype. We found that the ncs- 1 knock-out mutation completely suppressed the increase of isothermal tracking in $d a f-2$ (Fig. $5 a$ ). The result suggests that $d a f-2$ requires a function of ncs-1. However, we could not exclude the possibility that the $n c s-1$ gene is essential for learning under any conditions.

\section{Expression of age-1 in the AIY interneuron restores} isothermal tracking to the wild-type level in the age-1 mutant Expression of $n c s-1$ in the AIY neuron is essential for isothermal tracking. We reasoned that the age-1 gene may function with $n c s-1$ in the nervous system, including the AIY neuron. We tested whether expression of age-1 in neurons affects increased isothermal tracking in the age-1 mutant. First, we expressed the age-1 cDNA in all neurons, using the neuron-specific promoters unc$14 p$ and ric-19p. Expression of age-1 in all neurons restored increased isothermal tracking of age-1, although it did not affect the wild-type isothermal tracking (Fig. $5 b$ and data not shown). Thus, suppression by neuronal expression of age- 1 is specific to increased isothermal tracking. Moreover, expression of age- 1 in the AIY neuron suppressed the increase of isothermal tracking in the age-1 mutant (Fig. $5 b, t t x-3 p::$ age- 1 ), whereas expression in 10 neurons (mostly touch neurons; see mec-7::age-1) did not suppress it. The age-1 expression in AIY showed little suppression of the age-1 life-extension phenotype [mean \pm SEM lifespans were as follows: wild type, $12.2 \pm 0.6 \mathrm{~d}(n=49)$; age-1; $p(t t x-3::$ age- 1$)$, 
(a)

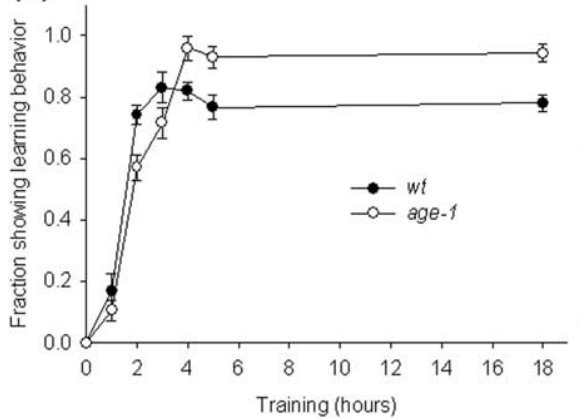

(b)

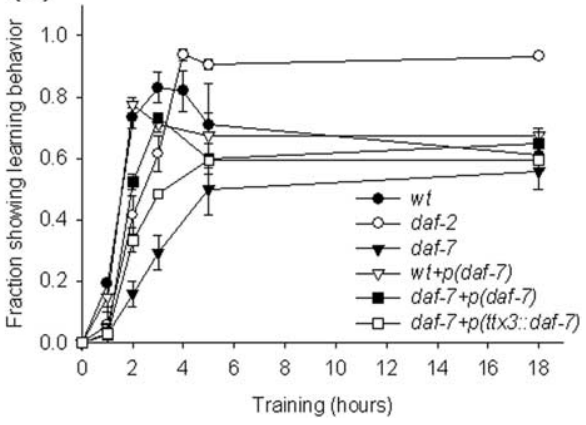

Figure 6. Learning after a series of training times. Young adults were conditioned for the time indicated across the set of experiments performed and tested for isothermal tracking in age-1(hx546) (a) and in daf-2(e1370), daf-7(e1372) (b), the transgenics expressing daf-7 as a transgene [wt $+p($ daf-7)], and the daf-7 transgenics expressing daf-7 [daf-7+ $+p($ daf-7)]. N2 was used as the wild-type (wt) strain. Mean \pm SEM of four experiments is shown. The age- 1 and daf- 2 mutants showed a significant increase in peak performance $(p<0.001)$, and they also showed a slight delay in learning speed at $2 \mathrm{~h}$ training $(p<0.01)$. The daf-7 mutant showed a larger delay at $2 \mathrm{~h}$ training $(p<0.001)$. This delay of the daf- 7 mutant was rescued by expression of daf -7 as a transgene $\left[\right.$ daf- $7+p\left(\right.$ daf-7)]. For $\boldsymbol{a}$, animals were grown at $25^{\circ}$. For $\boldsymbol{b}$, animals were grown under the shift-up condition.
$25.6 \pm 1.7 \mathrm{~d}(p<0.0001 ; n=48) ;$ age- 1 , $29.4 \pm 1.7 \mathrm{~d}(p<0.0001 ; n=44) ;$ age-1; $p$ (unc-14::age-1), $13.6 \pm 0.1 \mathrm{~d}$ ( $p=0.01$; $n=48)]$. Thus, it is likely that age- 1 functions in the AIY interneuron to modulate isothermal tracking but not lifespan. This is consistent with the fact that $n c s-1$ acts in the AIY neuron.

The daf-7 TGF $\beta$ mutants show deficits in acquisition

We also investigated isothermal tracking after a series of training times. The age-1 and daf-2 mutants showed a slight delay in acquiring isothermal tracking and increased association of paired stimuli after a $5 \mathrm{~h}$ training (Fig. 6a,b). The result suggests that the Age mutants increase steady state of association or prolonged retention (a)

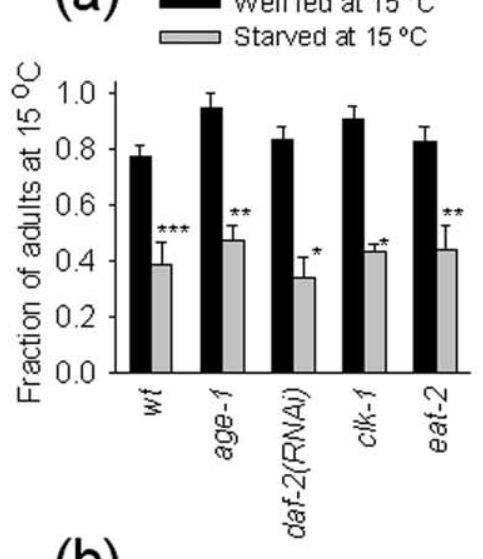

(b)

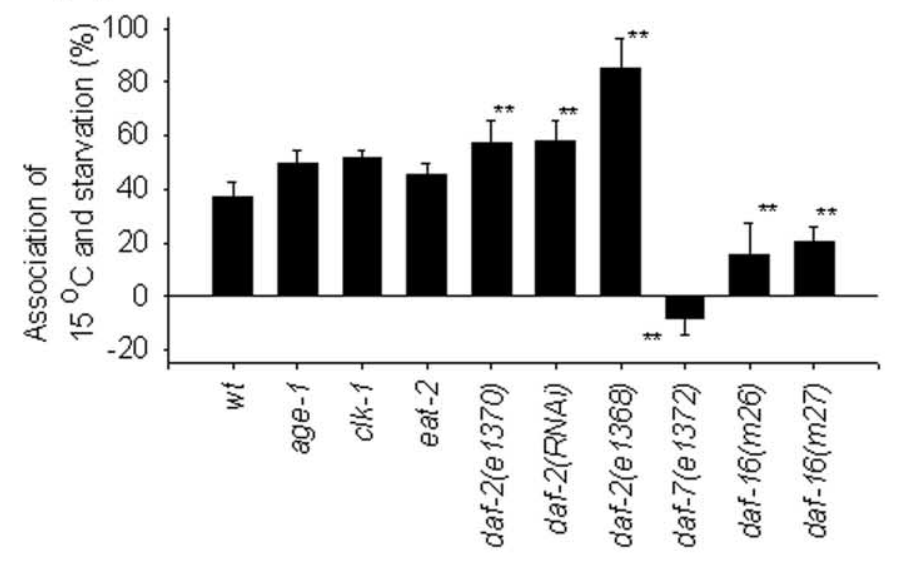

(c)

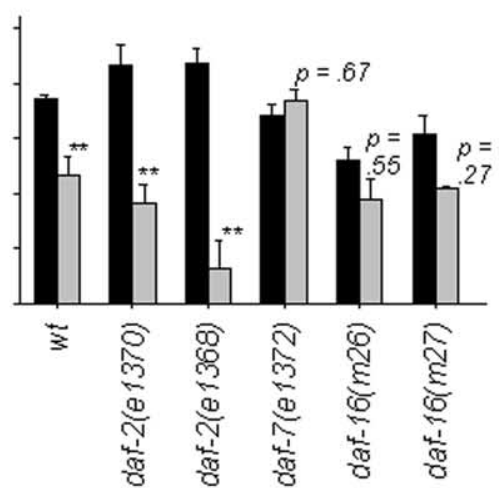

(d)
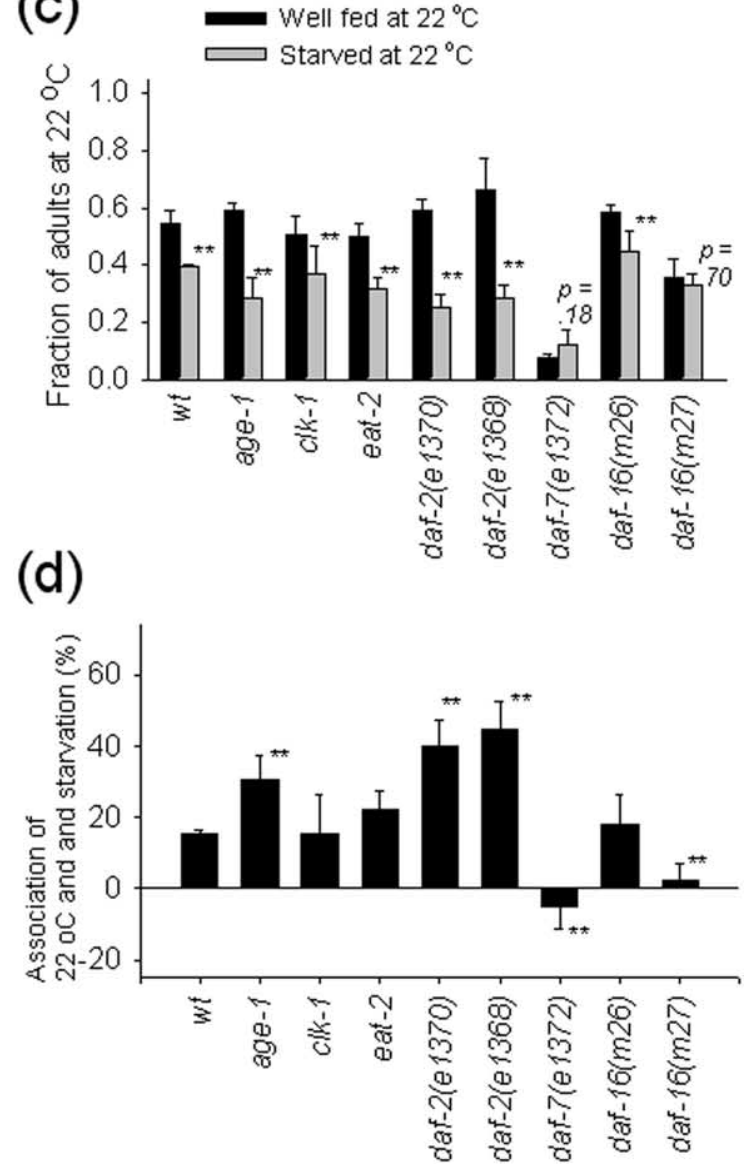

Figure 7. Association of paired temperature and starvation. $\boldsymbol{a}$, Thermotaxis of young adults when being conditioned at $15^{\circ} \mathrm{C}$. Adults were either conditioned at $15^{\circ} \mathrm{C}$ with food (well-fed at $\left.15^{\circ} \mathrm{C}\right)$ or incubated with food, followed by exposure to starvation at $15^{\circ} \mathrm{C}\left(\right.$ starved at $\left.15^{\circ} \mathrm{C}\right)$. Little or no naive adults showed thermotaxis to $15^{\circ} \mathrm{C}$. Well-fed adults showed a significant increase in thermotaxis in age-1 $(p=0.002 ; n=41)$, in daf-2(e1368) $(p=0.005 ; n=51)$, in daf-2(e1370) $(p=0.005 ; n=30)$, in clk-1 ( $p=0.04 ; n=175)$, and in eat-2 $(p=0.05 ; n=129)$. For other well-fed mutants, $p$ values were as follows: daf- $16(\mathrm{~m} 26)(p=0.56 ; n=82) ;$ daf- $16(\mathrm{~m} 27)(p=0.27 ; n=65) ;$ daf-7(e1372) $(p=0.67 ; n=95)$. See also Results. Left, animals were grown up at $25^{\circ} \mathrm{C}$. Right, animals were grown under the shift-up condition. $\boldsymbol{b}$, Percentage of the adults that coupled $15^{\circ} \mathrm{C}$ and starvation. The results of all the animals shown in $\boldsymbol{a}$ are combined and shown. $\boldsymbol{C}$, Thermotaxis of young adults when being conditioned at $22^{\circ} \mathrm{C}$. Adults were either conditioned at $22^{\circ} \mathrm{C}$ with food (well-fed at $22^{\circ} \mathrm{C}$ ) or incubated with food, followed by exposure to starvation at $22^{\circ} \mathrm{C}$ (starved at $22^{\circ} \mathrm{C}$ ). Little or no naive adults showed thermotaxis to $22^{\circ} \mathrm{C}$. Well-fed adults did not show a significant difference in thermotaxis except for daf-7 $(p<0.001 ; n=136)$. Animals were grown at $17^{\circ} \mathrm{C}$. $\boldsymbol{d}$, Percentage of the adults that coupled $22^{\circ} \mathrm{C}$ and starvation. Mean and $\mathrm{SEM}$ of three or more experiments are shown. $p$ values show the significance against the wild type (wt) determined by the Newman-Keuls test. Asterisks show significance levels (for specific $p$ values, see Fig. 5) between well-fed and starved adults. Young adults were used (see Materials and Methods). 
of thermotaxis, although there is a modest delay in acquisition.

In $C$. elegans, the insulin/IGF-1 and daf-7 TGF $\beta$ neuroendocrine signals regulate metabolic control, feeding behaviors, and formation of dauer larvae (diapause stage) (Riddle and Alberts, 1997). The daf-7 and daf-2 mutants show many common phenotypes, including a metabolic shift to fat accumulation, altered feeding behaviors, and constitutive dauer formation. If one or more of the common phenotypes increase isothermal tracking, one should observe increased association of paired stimuli in the daf-7 mutant. As shown in Figure 4, the daf-7 TGF $\beta$ mutant, daf-7(e1372), did not show increased isothermal tracking, but instead the daf-7 mutant learned slower than the wild type $(p<$ 0.001 ) (Fig. 6b). The daf-7(m62) also showed similar results (data not shown). This reduced acquisition in the daf-7 mutant was rescued by expression of the daf-7 gene (Fig. $6 b$ ). The results rule out the possibility that the increased learning association is conferred by altered metabolic control or other food-associated processes.

The Age mutations increase association of paired temperature and starvation, but the $d a f-7$ mutant impairs the association We examined another type of thermotaxis learning paradigm that associates temperature and starvation [i.e., temperaturefood $(-)$ association]. The starvation conditioning at a temperature triggers an avoidance response against the conditioning temperature. After being conditioned at a temperature with food [temperature-food $(+)$ conditioning], animals were starved at the temperature [temperature-food $(-)$ conditioning or temperature-starvation conditioning] (Fig. 7a,c). We measured the percentage of the conditioned animals that avoided the temperature (Fig. $7 b, d$ ).

When conditioned at $15^{\circ} \mathrm{C}$, the daf- 2 mutants showed increases in the fraction of animals showing temperature-starvation [or temperature-food $(-)$ ] association (Fig. 7b). An allele of daf-2, e1368, increased the temperature-food $(-)$ association by more than twofold, whereas daf-2(e1370) showed a modest increase (Fig. 7b). daf-2(e1368) (a class 1 allele) has a mutation in the ligand binding domain, whereas daf-2(e1370) (a class 2 allele) is more pleiotropic than daf-2(e1368) and has a mutation in the kinase domain, which presumably affects downstream signaling (Kimura et al., 1997; Gems et al., 1998). To test the possibility that the class 1 allele has a strong effect on the temperature-food $(-)$ association, we further examined daf-2(RNAi), which should show class 1 phenotype and lower the daf-2 activity without changing the ligand specificity. daf-2(RNAi) increased the temperature-food $(-)$ association similar to the daf-2(e1370). Thus, the results suggest that certain insulin-like ligands may be important for temperature-food $(-)$ associative learning behavior. Consistent with the results of daf-2(e1370), there was little increase in the temperature-food $(-)$ association in the age-1 mutation (Fig. $7 b$ ), which is expected to have a downstream effect on the signal from DAF-2. Note that conditioned age-1 and daf-2 animals show locomotion behaviors similar to the wild-type animals, inside and outside of the training temperature (for well-fed animals, see Fig. $9 a, b$; for starved animals, data not shown).

Interestingly, when animals were conditioned at $22^{\circ} \mathrm{C}$ with starvation, both the age-1 and daf-2 mutants showed increased temperature-starvation association (Fig. $7 c, d$ ). The increased association was larger than those under the $15^{\circ} \mathrm{C}$ conditioning in the mutants. Because the age- 1 and daf- 2 mutants show stronger phenotypes at $22^{\circ} \mathrm{C}$ (semirestrictive temperature) than $15^{\circ} \mathrm{C}$ (permissive temperature), we speculate that the conditioning
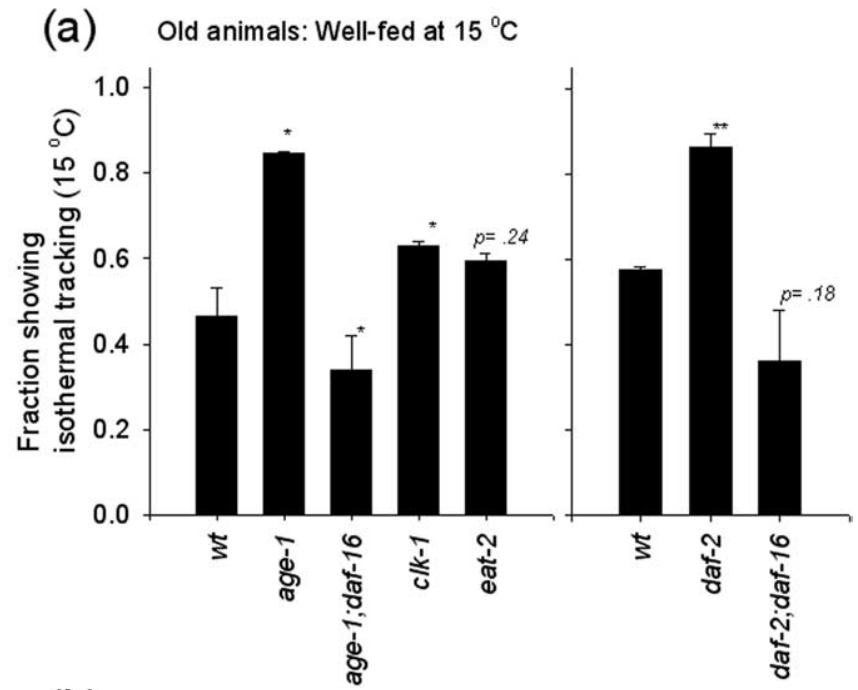

(b)

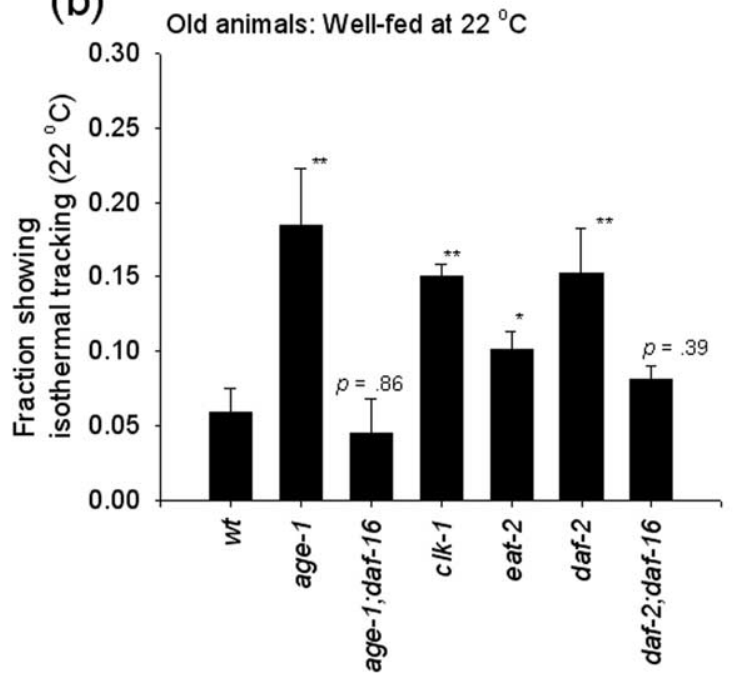

Figure 8. Isothermal tracking of old animals. $\boldsymbol{a}$, Isothermal tracking $\left(15^{\circ} \mathrm{C}\right)$ of various lifeextending mutants (age-1, clk-1, and eat-2). Nine-day-old animals grown at $25^{\circ} \mathrm{C}$ were used. Locomotion defective animals were excluded from the results. The number of animals tested was as follows: $60, \mathrm{N2} ; 38$, age-1; 78, clk-1; and 79, eat-2. For $p$ values shown by asterisks, see Figure 5. The number of animals tested was as follows: 87, N2; 104, daf-2(e1370); 85, daf-2; daf-16. Animals were grown at $25^{\circ} \mathrm{C}$ (left) and under the shift-up condition (right). Day 5 animals after $L 4$ larval stage were used (the late phase of reproduction). $\boldsymbol{b}$, Isothermal tracking $\left(22^{\circ} \mathrm{C}\right)$ of the life-extending mutants. The number of animals tested was as follows: left panel, 106, N2; 141, age-1; 33, clk-1,37, age-1; daf-16; and 34, eat-2; 40, daf-2; and 36, daf-2; daf-16. Animals were grown up at $17^{\circ} \mathrm{C}$, and day 7 animals after $L 4$ larval stage were used (the late phase of reproduction). wt, Wild type.

temperatures may cause the difference in the age- 1 and $d a f-2$ mutants.

The fraction of animals that avoided the conditioning temperature did not increase in other life-extending mutants ( $c l k-1$ and eat-2) when conditioned at $15^{\circ} \mathrm{C}$ (Fig. $7 b$ ) and at $22^{\circ} \mathrm{C}$ (Fig. $7 d$ ). The clk-1 and eat-2 mutants belong to other classes of lifeextending mutants; the $c l k-1$ mutant shows reduction in mitochondrial metabolism, whereas the eat-2 mutant shows calorie restriction (Lakowski and Hekimi, 1998). The results argue against the possibility that the secondary effects of life extension increase in temperature-food $(-)$ association in the lifeextending mutants. The $c l k-1$ and eat-2 mutants showed significant increase in the fraction of temperature-food $(+)$ conditioned animals showing thermotaxis behavior (Fig. 7a). 
(a)
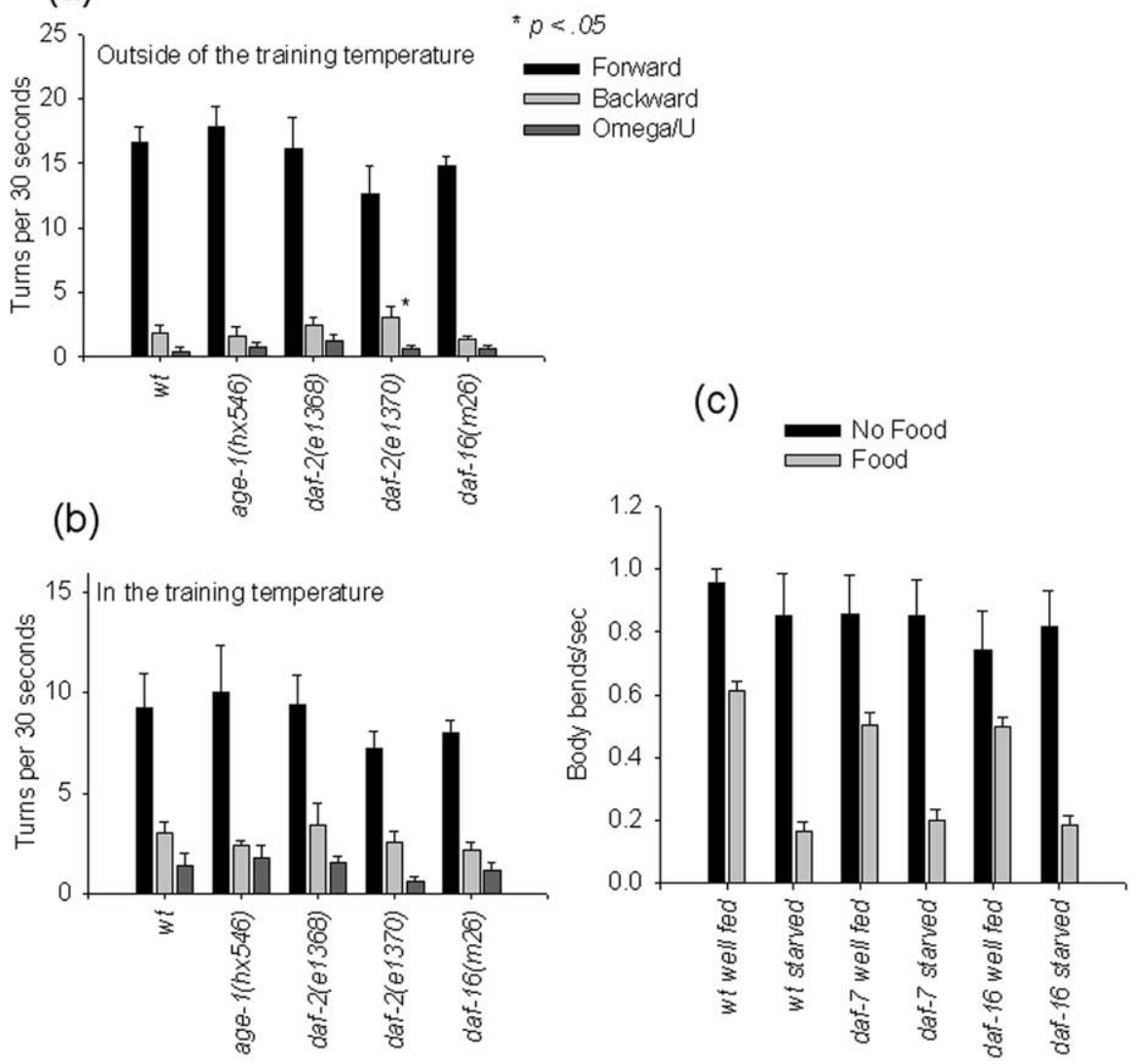

Figure 9. Detailed locomotion behaviors. $\boldsymbol{a}$, Turns of conditioned young animals outside of the training temperature area. After conditioned with food and temperature, three kinds of turns (forward turns, backward turns, and Omega/U turns) were scored in 30 s intervals. Approximately 10 animals were tested. $\boldsymbol{b}$, Turns of conditioned young adults in the training temperature area. The results of temperature-food (-) conditioned animals were shown in $\boldsymbol{a}$ and $\boldsymbol{b}$. $\boldsymbol{c}$, Slowing responses to food. Well-fed and starved daf-7 animals were tested. The wild type (N2) and the daf-7 mutant showed significant basal and enhanced slowing response $(p<0.001)$. There was no significant difference between the following comparisons: between wild type and daf-7in the slowing responses to food ( $p=0.06$ for the basal slowing response of well-fed animals on food; $p=0.47$ for the enhanced slowing response of starved animals on food); between well-fed and starved animals within the same strains ( $p=0.92$ for N2; $p=0.91$ for daf-7); between N2 and daf-7 with the same conditions ( $p>0.06)$. All assays include the results of $\sim 10$ animals. Animals were grown under the shift-up condition. wt, Wild type.

Importantly, in old animals, the mutants showed an increase in the consistency of isothermal tracking (Fig. 8), suggesting that both $c l k-1$ and eat-2 mutants delay age-related declines of thermotaxis learning behavior.

The results suggest that the mechanism of temperature-starvation association involves the function specific to the insulin/ IGF-1 pathway. In addition, after the $15^{\circ} \mathrm{C}$ starvation conditioning for a shorter time $(1 \mathrm{~h})$ than the standard condition $(2.5 \mathrm{~h})$, the age- 1 and $d a f-2$ mutants but not the wild type showed significant $15^{\circ} \mathrm{C}$ avoidance [fraction of adults at $15^{\circ} \mathrm{C}$ were as follows: age-1 ( $h \times 546), 43.7 \pm 0.01 \%$ ( $46 \%$ increase in association; $n=39$; $p=0.01)$; daf-2(RNAi), $48.5 \pm 0.03 \%$ (49\% increase in association; $n=37 ; p=0.02)$; wild type, $78.5 \pm 0.05 \%$ (3\% increase in association; $n=37)$ ]. We speculate that the age- 1 and daf- $2 \mathrm{mu}-$ tants show increased response to starvation. Thus, the mechanism of temperature-food association is different from that of temperature-starvation association.

Last, the daf- 7 mutant showed normal $15^{\circ} \mathrm{C}$ food pairing (Fig. 7a) but failed to form $22^{\circ} \mathrm{C}$ food pairing (Fig. 7 c). It is unlikely that the phenotypes are caused by cryophilicity to $15^{\circ} \mathrm{C}$ because the daf- 7 animals showed normal thermotaxis to $22^{\circ} \mathrm{C}$ after conditioning for $2 \mathrm{~d}$ (data not shown). We speculate that the pheno- types are rather caused by the conditioning temperature, which is semirestrictive for the daf-7 mutants. The daf-7 mutants also failed to form temperature-food $(-)$ pairing (Fig. 7a,b). The daf-7 animals showed normal response to food (Fig. 9c) and normal thermotaxis (data not shown). Thus, the daf-7 mutant shows deficits in temperature-food $(+)$ association and in temperature-food $(-)$ association, depending on the conditioning temperature.

\section{Chemosensory learning behavior in age- 1 and $d a f-2$}

We have further investigated the effect of the age- 1 and daf-2 mutations on simple chemotaxis and chemotaxis adaptation. We used benzaldehyde as a volatile attractant for chemotaxis assays; benzaldehyde has been used extensively in previous studies (Bargmann et al., 1993; Troemel et al., 1997; Nuttley et al., 2002). Young adults synchronized at the L4 stage were used. As shown in Figure 10, naive age-1 and daf-2 animals show a higher CI than the wild-type animals at the standard concentration ( $1 \%$ benzaldehyde), whereas the mutants showed normal chemotaxis to the diluted benzaldehyde. The results suggest two possibilities: (1) the Age mutants have increased ability to sense benzaldehyde; and (2) the mutants show increased attraction at certain concentration of the odor. We could not determine the possibility because of the high variability in the dose-response experiments (supplemental Fig. 1, available at www.jneurosci.org as supplemental material).

After being conditioned with benzaldehyde in the absence of food [benzaldehyde-food $(-)$ conditioning] for $1 \mathrm{~h}$, the daf-2 animals showed higher avoidance to benzaldehyde (or a lower CI) than the wild type (Fig. 10). Thus, the daf-2 mutants show an increase in the degree of chemosensory adaptation, likely through altered ability to sense benzaldehyde. The difference between age-1 and the wild type was not statistically significant (Fig. 10 and its legend). After $2 \mathrm{~h}$ of conditioning, all of the mutant and control animals showed a similar CI. Thus, we used the $2 \mathrm{~h}$ conditioning to further assess for reconditioning with food. Animals conditioned for $2 \mathrm{~h}$ were subjected to the benzaldehyde-food $(+)$ reconditioning and were tested to what degree they showed attraction to benzaldehyde. The Age and wild-type animals showed similar CI in the benzaldehyde-food $(+)$ reconditioning (Fig. 10). Thus, the Age mutants did not show any difference in the reconditioning experiments.

\section{Discussion}

The Age mutations with the insulin/IGF-1 signaling system increase resistance to a variety of environmental stressors and infectious diseases (Johnson et al., 1996; Martin et al., 1996; Murakami and Johnson, 1996; Garsin et al., 2003) and other biological processes. The effect of the Age mutations on behav- 

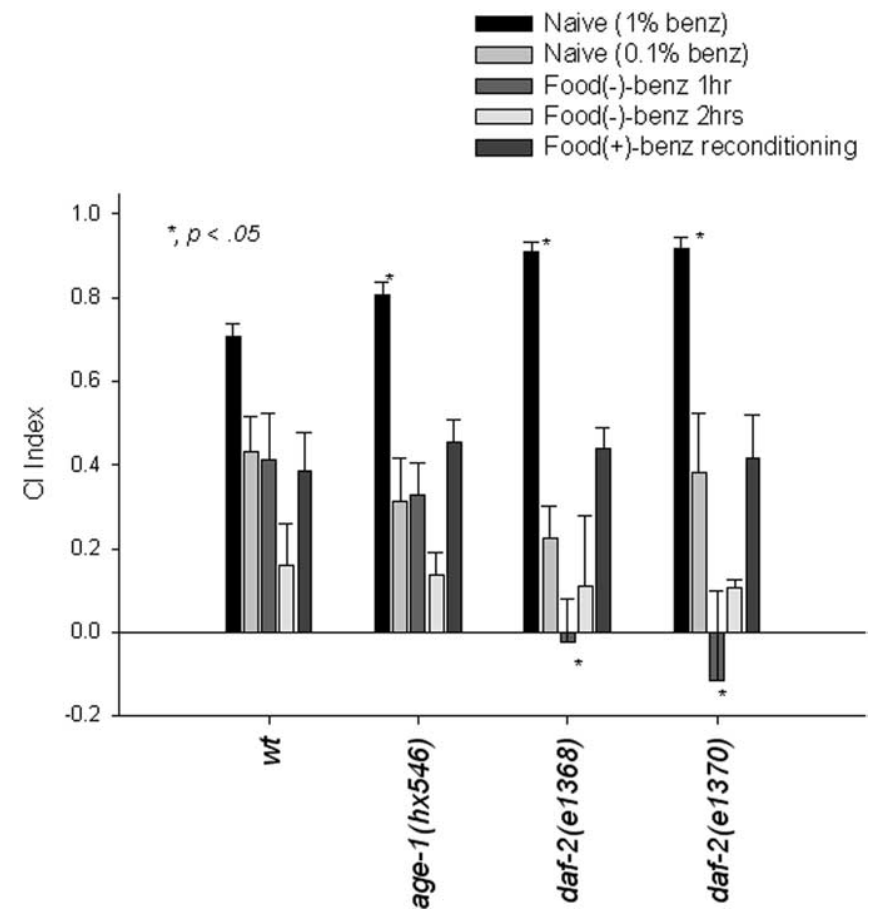

Figure 10. Chemosensory learning behavior of the Age mutants. Cl of young adults is shown. Developmentally synchronized animals were assessed for chemotaxis to benzaldehyde (benz). Naive animals were tested for chemotaxis to benzaldehyde, ranging from 0.1 to $1.0 \%$ (this figure and supplemental Fig. 2, available at www.jneurosci.org as supplemental material). For chemotaxis adaptation, animals were conditioned with benzaldehyde without food for $1 \mathrm{~h}$ [Food(-)-benz $1 \mathrm{hr}$ ] or for $2 \mathrm{~h}$ [Food(-)-benz $2 \mathrm{hrs}$ ]. Animals with $2 \mathrm{~h}$ conditioning were further reconditioned for $1 \mathrm{~h}$ with benzaldehyde and food [Food ( +)-benz reconditioning]. The significance level of each condition between wild type (wt) and each mutant were shown. For $1 \mathrm{~h}$ conditioning of food $(-)$ - benzaldehyde, the age- 1 did not show significant difference from the wild type ( $p=0.74 ; n=427$ for N2; $n=299$ for age-1). In each strain, $\mathrm{Cl}$ of naive animals to $1 \%$ benzaldehyde was higher than those of conditioned animals $(p<0.01)$. Mean and SEM of three or more replications are shown. Animals were grown under the shift-up condition.

ioral plasticity, such as learning and memory, had not been tested previously. Our results suggest that the Age mutations influence learning behavior in several ways.

First, the age- 1 mutant participates in the aging process and has a role in learning. The age-1 mutant showed delayed agerelated decline in isothermal tracking, which resulted in a threefold extension of the period with high levels of isothermal tracking. The effect was dramatic compared with life extension and the extension of other physiological health spans by the age- 1 mutant (Johnson, 1990; Murakami and Johnson, 1996; Huang et al., 2004; this study). The age-1 and daf-2 mutants may lead to enhanced maintenance of neural mechanisms and increased consistency of learning and memory. It has been shown that the mutants demonstrate an enhanced stress-defense system (for review, see Johnson et al., 1996; Murakami and Johnson, 2003). Thus, although it requires additional careful experiments, we speculate that reducing insulin/IGF-1 signal may be a powerful aid for the prevention of age-related functional declines in the nervous system and/or dementia. Note that other classes of lifeextending mutants, $c l k-1$ and eat-2, show a similar increase in isothermal tracking.

Second, the age- 1 and $d a f-2$ mutants further increase the consistency of temperature-food $(+)$ learning behavior (or steadystate association of paired temperature and food) in early life. The increased learning consistency appears common in the other lifeextending mutants (clk-1 and eat-2). Previously, we showed that reducing oxidative stress increases isothermal tracking in young adults (Murakami and Murakami, 2005), which may contribute to the learning consistency in the mutants. Interestingly, age-1 is required in a single type of interneuron, AIY, which is a key component of the thermosensory circuit.

Third, the daf-2 mutants increase the consistency of temperature-food $(-)$ learning behavior. There was little increase in this type of learning behavior in other life-extending mutants (age-1, clk-1, and eat-2). It is possible that the increased temperaturefood $(-)$ association depends on certain daf-2 ligands (insulinlike peptides), because the ligand-binding mutation of daf2(e1368) has a dramatic effect. Last, both age-1 and daf-2 affect chemotaxis to an odor, benzaldehyde. The daf-2 mutants, but not the age-1 mutant, affect chemosensory learning behavior [i.e., benzaldehyde-food (-) association]. Thus, the daf-2 mutants increase chemotaxis to benzaldehyde and increase the odorfood $(-)$ learning behavior. In contrast, the age-1 mutant may alter certain chemosensory learning.

After conditioning with food, the Age mutants show an increase in consistency of thermotaxis learning behavior, although acquisition and food response may be modestly delayed. The interpretation of the delayed acquisition requires careful consideration because alterations in response to stimuli (or sensory response) may alter acquisition of behavior or association of paired stimuli. It has been suggested that the insulin/IGF-1 and daf-7 TGF $\beta$ pathways in part mediate food and temperature signals (Sze et al., 2000; Nuttley et al., 2002). The mutations in age-1, $d a f-2$, and $d a f-7$ show similar response triggered by temperature and starvation, including dauer-larvae formation and feedingrelated metabolic phenotypes (Riddle and Alberts, 1997). Importantly, the daf-7 mutant shows normal locomotion response to food (basal and enhanced slowing response) and normal thermotaxis to cultivation temperature. The daf-7 mutant may affect more downstream processes than sensory perception. The straightforward interpretation is that daf-7 modulates acquisition, although it is not easy to interpret the delay of acquisition in the Age mutants. The age-1 mutant shows normal response to food and shows a high steady-state thermotaxis learning behavior. If the mutants show increased ability to sense temperature (or food), the Age mutant should have increased acquisition of learning behavior. Our result of delayed acquisition in age- 1 and $d a f-2$ argues against the possibility that increased sensory ability causes increased consistency of learning in the mutants. Thus, the Age mutants affect acquisition in a complex way, perhaps in part through either altered sensory ability or altered learning.

In Figure 11, we summarize our models for the modulation of learning behavior. Increased temperature-food $(+)$ association was observed in various Age mutants, including mutants in the insulin/IGF-1 pathway (age-1 and daf-2), mutants with reduced oxidative stress $(c l k-1)$, and a mutant with calorie restriction (eat2). Thus, we speculate that the effects of life extension, or improved neuronal maintenance, confer the increase in temperature-food $(-)$ association. Importantly, oxidative stress is a determinant of levels of the steady-state temperature-food $(+)$ association (Murakami and Murakami, 2005). Thus, the results that AIY expression of age-1 restores learning behavior suggest that protecting AIY interneuron may be essential for the temperature-food $(+)$ phenotype in the Age mutants. Alternatively, it is also possible that the insulin/IGF-1 pathway expressed in AIY plays a role in mediating the information about level of oxidative stress, which determines levels of temperature-food $(+)$ association. The possibility appears consistent with the observation that the jnk-1 gene mediates oxidative-stress signal and also interlocks 


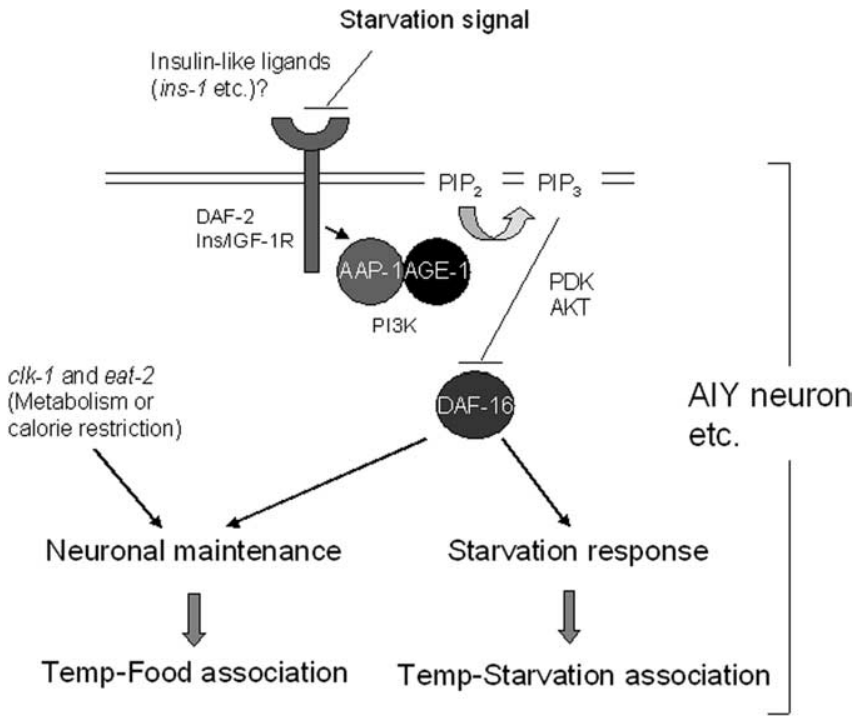

Figure 11. A model of thermotaxis modulated by the life-extending mutants. In the model, temperature-food [temperature-food $(+)$ ] association is modulated by the effects of life extension in the Age mutants. It is also possible that oxidative stress may modulate temperaturefood association. Temperature-starvation [temperature-food (-)] association is modulated by a different mechanism, such as increased response to starvation. AGE- 1 is a catalytic subunit of phasphatidylinositol-3-0H kinase (PI3K), and AAP-1 (age-1-associated protein) is a regulatory subunit of PI3K. DAF-16 is a FOX0/forkhead transcription factor. Ins/IGF-1R, Insulin/IGF-1 receptor; PIP2, phosphatidylinositol 4,5-biphosphate; PIP3, phosphatidylinositol 3,4,5triphosphate. For details, see Discussion.

with the insulin/IGF-1 pathway (Oh et al., 2005); the jnk-1 gene is expressed in AIY (Wenick and Hobert, 2004).

In contrast, temperature-food $(-)$ association is modulated by the insulin/IGF-1 pathway in a different mechanism (Fig. 11), which is affected by the age- 1 and daf- 2 mutations but not by the clk-1 and eat-2 mutations. It is plausible that increased temperature-food $(-)$ association is mediated by increased starvation response in the age- 1 and daf- 2 mutants. The increased starvation response is consistent with the previous observations that the age- 1 and daf- 2 mutations cause starvation-related phenotypes, as mentioned previously (Riddle and Alberts, 1997; Sze et al., 2000) (K. Bessinger and S. Murakami, unpublished observation).

In $C$. elegans, the insulin/IGF-1 signal may have a role in mediating environmental cues to influence aging and various other biological processes. Ablation of certain chemosensory neurons (e.g., ASI and ASG) increases longevity by up to $33 \%$, likely through affecting the insulin/IGF-1 signal (Alcedo and Kenyon, 2004). Previous studies suggest that the insulin/IGF-1 signal and the TGF $\beta$ signal play a role in responses to environmental changes related to food supply (Riddle and Alberts, 1997; Sze et al., 2000), pheromone (Sze et al., 2000), and environmental stress (Lithgow et al., 1995; Murakami and Johnson, 1996, 2001; Henderson and Johnson, 2001; Alcedo and Kenyon, 2004). Interestingly, high humidity reduces thermotaxis learning behavior, perhaps through sensory processing; insulin/IGF-1 appears to mediate the effects of humidity (H. Murakami and S. Murakami, unpublished observation). Humidity at $100 \%$ did not cause changes in the locomotion rate and abnormal thermotaxis, although humidity is a factor to increase reversal locomotion (Zhao et al., 2003). Thus, it remains to be determined as to how humidity influences functions of thermotaxis, including association of paired stimuli and motor activity. It is noteworthy that the insulin/IGF-1 pathway functions in the nervous system as well as in other tissues (Wolkow et al., 2000).
It has been a controversial issue that the insulin/IGF-1 hormonal signal may modulate learning because metabolic control by the signal indirectly affects nervous function (Craft et al., 1996; Wickelgren, 1998; Gerozissis et al., 2001; Obici et al., 2002). Our findings are suggestive of direct roles of insulin/IGF-1 signal in modulation of learning. Many animal species can learn to associate a variety of stimuli, including the food stimulus. This form of learning is called associative learning, which is an ancient and conserved function to ensure behavioral plasticity in a changing environment. We suggest that environmental changes, in turn, affect performance of learning through the hormonal signal(s). This study also highlights a hormonal modulation of learning by environment, which may be an essential function of behavioral plasticity.

\section{References}

Alcedo J, Kenyon C (2004) Regulation of C. elegans longevity by specific gustatory and olfactory neurons. Neuron 41:45-55.

Bargmann CI, Hartwieg E, Horvitz HR (1993) Odorant-selective genes and neurons mediate olfaction in C. elegans. Cell 74:515-527.

Barsyte D, Lovejoy DA, Lithgow GJ (2001) Longevity and heavy metal resistance in daf-2 and age-1 long-lived mutants of Caenorhabditis elegans. FASEB J 15:627-634.

Craft S, Newcomer J, Kanne S, Dagogo-Jack S, Cryer P, Sheline Y, Luby J, Dagogo-Jack A, Alderson A (1996) Memory improvement following induced hyperinsulinemia in Alzheimer's disease. Neurobiol Aging 17:123-130.

Dillin A, Crawford DK, Kenyon C (2002) Timing requirements for insulin/ IGF-1 signaling in C. elegans. Science 298:830-834.

Fraser AG, Kamath RS, Zipperlen P, Martinez-Campos M, Sohrmann M, Ahringer J (2000) Functional genomic analysis of C. elegans chromosome I by systematic RNA interference. Nature 408:325-330.

Garsin DA, Villanueva JM, Begun J, Kim DH, Sifri CD, Calderwood SB, Ruvkun G, Ausubel FM (2003) Long-lived C. elegans daf-2 mutants are resistant to bacterial pathogens. Science 300:1921.

Gems D, Sutton AJ, Sundermeyer ML, Albert PS, King KV, Edgley ML, Larsen PL, Riddle DL (1998) Two pleiotropic classes of daf-2 mutation affect larval arrest, adult behavior, reproduction and longevity in Caenorhabditis elegans. Genetics 150:129-155.

Gerozissis K, Rouch C, Lemierre S, Nicolaidis S, Orosco M (2001) A potential role of central insulin in learning and memory related to feeding. Cell Mol Neurobiol 21:389-401.

Gomez M, De Castro E, Guarin E, Sasakura H, Kuhara A, Mori I, Bartfai T, Bargmann CI, Nef P (2001) $\mathrm{Ca}^{2+}$ signaling via the neuronal calcium sensor-1 regulates associative learning and memory in C. elegans. Neuron 30:241-248.

Henderson S, Johnson TE (2001) daf-16 integrates developmental and environmental inputs to mediate aging in the nematode Caenorhabditis elegans. Curr Biol 11:1975-1980.

Hobert O, Mori I, Yamashita Y, Honda H, Ohshima Y, Liu Y, Ruvkun G (1997) Regulation of interneuron function in the C. elegans thermoregulatory pathway by the ttx-3 LIM homeobox gene. Neuron 19:345-357.

Holzenberger M, Dupont J, Ducos B, Leneuve P, Geloen A, Even PC, Cervera P, Le Bouc Y (2003) IGF-1 receptor regulates lifespan and resistance to oxidative stress in mice. Nature 421:182-187.

Honda Y, Honda S (1999) The daf-2 gene network for longevity regulates oxidative stress resistance and $\mathrm{Mn}$-superoxide dismutase gene expression in Caenorhabditis elegans. FASEB J 13:1385-1393.

Huang C, Xiong C, Kornfeld K (2004) Measurements of age-related changes of physiological processes that predict lifespan of Caenorhabditis elegans. Proc Natl Acad Sci USA 101:8084-8089.

Johnson TE (1990) Increased life-span of age-1 mutants in Caenorhabditis elegans and lower Gompertz rate of aging. Science 249:908-912.

Johnson TE, Lithgow GJ, Murakami S (1996) Hypothesis: interventions that increase the response to stress offer the potential for effective life prolongation and increased health. J Gerontol A Biol Sci Med Sci 6:B392-B395.

Kenyon C, Chang J, Gensch E, Rudner A, Tabtiang R (1993) A C. elegans mutant that lives twice as long as wild type. Nature 366:461-464.

Kimura KD, Tissenbaum HA, Liu Y, Ruvkun G (1997) daf-2, an insulin 
receptor-like gene that regulates longevity and diapause in Caenorhabditis elegans. Science 277:942-946.

Koga M, Take-uchi M, Tameishi T, Ohshima Y (1999) Control of DAF-7 TGF- $\beta$ expression and neuronal process development by a receptor tyrosine kinase KIN-8 in Caenorhabditis elegans. Development $126: 5387-5398$

Lakowski B, Hekimi S (1998) The genetics of caloric restriction in Caenorhabditis elegans. Proc Natl Acad Sci USA 95:13091-13096.

Larsen PL (1993) Aging and resistance to oxidative damage in Caenorhabditis elegans. Proc Natl Acad Sci USA 90:8905-8909.

Larsen PL, Albert PS, Riddle DL (1995) Genes that regulate both development and longevity in Caenorhabditis elegans. Genetics 139:1567-1583.

Lee SP, So CH, Rashid AJ, Varghese G, Cheng R, Lanca AJ, O’Dowd BF, George SR (2004) Dopamine D1 and D2 receptor co-activation generates a novel phospholipase C-mediated calcium signal. J Biol Chem 279:35671-35678.

Libina N, Berman JR, Kenyon C (2003) Tissue-specific activities of C. elegans DAF-16 in the regulation of lifespan. Cell 115:489-502.

Lin K, Dorman JB, Rodan A, Kenyon C (1997) daf-16: an HNF-3/forkhead family member that can function to double the life-span of Caenorhabditis elegans. Science 278:1319-1322.

Lithgow GJ, White TM, Melov S, Johnson TE (1995) Thermotolerance and extended life-span conferred by single-gene mutations and induced by thermal stress. Proc Natl Acad Sci USA 92:7540-7544.

Martin GM, Austad SN, Johnson TE (1996) Genetic analysis of ageing: role of oxidative damage and environmental stresses. Nat Genet 13:25-34.

McElwee J, Bubb K, Thomas JH (2003) Transcriptional outputs of the Caenorhabditis elegans forkhead protein DAF-16. Aging Cell 2:111-121.

Mori I (1999) Genetics of chemotaxis and thermotaxis in the nematode Caenorhabditis elegans. Annu Rev Genet 33:399-422.

Mori I, Ohshima Y (1995) Neural regulation of thermotaxis in Caenorhabditis elegans. Nature 376:344-348.

Murakami S, Johnson TE (1996) A genetic pathway conferring life extension and resistance to UV stress in Caenorhabditis elegans. Genetics 143:1207-1218.

Murakami S, Johnson TE (2001) The OLD-1 positive regulator of longevity and stress resistance is under DAF-16 regulation in Caenorhabditis elegans. Curr Biol 11:1517-1523.

Murakami S, Johnson TE (2003) Regulation of life span in model organisms. Curr Genomics 4:63-74.

Murakami S, Murakami H (2005) The effects of oxidative stress on learning behavior in C. elegans. Neurobiol Aging 26:899-905.

Murakami S, Salmon A, Miller RA (2003) Multiplex stress resistance in cells from long-lived dwarf mice. FASEB J 17:1565-1566.

Murphy CT, McCarroll SA, Bargmann CI, Fraser A, Kamath RS, Ahringer J, Li H, Kenyon C (2003) Genes that act downstream of DAF-16 to influence the lifespan of Caenorhabditis elegans. Nature 424:277-283.

Nuttley WM, Atkinson-Leadbeater KP, van der Kooy D (2002) Serotonin mediates food-odor associative learning in the nematode Caenorhabditis elegans. Proc Natl Acad Sci USA 99:12449-12454.

Obici S, Feng Z, Karkanias G, Baskin DG, Rossetti L (2002) Decreasing hypothalamic insulin receptors causes hyperphagia and insulin resistance in rats. Nat Neurosci 5:566-572.

Ogg S, Paradis S, Gottlieb S, Patterson GI, Lee L, Tissenbaum HA, Ruvkun G
(1997) The Fork head transcription factor DAF-16 transduces insulinlike metabolic and longevity signals in C. elegans. Nature 389:994-999.

Oh SW, Mukhopadhyay A, Syrzikapa N, Jiang F, Davis RJ, Tissenbaum HA (2005) JNK regulates lifespan in Caenorhabditis elegans by modulating nuclear translocation of forkhead transcription factor/DAF-16. Proc Natl Acad Sci USA 102:4494-4499.

Ookuma S, Fukuda M, Nishida E (2003) Identification of a DAF-16 transcriptional target gene, scl-1, that regulates longevity and stress resistance in Caenorhabditis elegans. Curr Biol 13:427-431.

Pletcher SD, Macdonald SJ, Marguerie R, Certa U, Stearns SC, Goldstein DB, Partridge L, Macdonald SJ, Marguerie R, Certa U, Stearns SC, Goldstein DB, Partridge L (2002) Genome-wide transcript profiles in aging and calorically restricted Drosophila melanogaster. Curr Biol 12:712-723.

Ren P, Lim CS, Johnsen R, Albert PS, Pilgrim D, Riddle DL (1996) Control of C. elegans larval development by neuronal expression of a TGF-beta homolog. Science 274:1389-1391.

Riddle DL, Alberts PS (1997) Genetic and environmental regulation of dauer larva development. In: C. elegans II (Riddle DL, Blumenthal T, Meyer BJ, Priess JR, eds), pp739-768. Cold Spring Harbor, NY: Cold Spring Harbor Laboratory.

Satterlee JS, Sasakura H, Kuhara A, Berkeley M, Mori I, Sengupta P (2001) Specification of thermosensory neuron fate in C. elegans requires $t \mathrm{tx}-1$, a homolog of otd/Otx. Neuron 31:943-956.

Sawin ER, Ranganathan R, Horvitz HR (2000) C. elegans locomotory rate is modulated by the environment through a dopaminergic pathway and by experience through a serotonergic pathway. Neuron 26:619-931.

Scharenberg AM, Kinet JP (1998) PtdIns-3,4,5-P3: a regulatory nexus between tyrosine kinases and sustained calcium signals. Cell 94:5-8.

Simmer F, Tijsterman M, Parrish S, Koushika SP, Nonet ML, Fire A, Ahringer J, Plasterk RH (2002) Loss of the putative RNA-directed RNA polymerase RRF-3 makes C. elegans hypersensitive to RNAi. Curr Biol 12:1317-1319.

Sze JY, Victor M, Loer C, Shi Y, Ruvkun G (2000) Food and metabolic signalling defects in a Caenorhabditis elegans serotonin-synthesis mutant. Nature 403:560-564.

Timmons L, Court DL, Fire A (2001) Ingestion of bacterially expressed dsRNAs can produce specific and potent genetic interference in Caenorhabditis elegans. Gene 263:103-112.

Timmons L, Hiroaki T, Mello, Craig M, Fire A (2003) Inducible systemic RNA silencing in Caenorhabditis elegans. Mol Biol Cell 14:2972-2983.

Troemel ER, Kimmel BE, Bargmann CI (1997) Reprogramming chemotaxis responses: sensory neurons define olfactory preferences in C. elegans. Cell 91:161-169.

Vanfleteren JR (1993) Oxidative stress and ageing in Caenorhabditis elegans. Biochem J 292:605-608.

Wenick AS, Hobert O (2004) Genomic cis-regulatory architecture and trans-acting regulators of a single interneuron-specific gene battery in $C$. elegans. Dev Cell 6:757-770.

Wickelgren I (1998) Tracking insulin to the mind. Science 280:517-519.

Wolkow CA, Kimura KD, Lee MS, Ruvkun G (2000) Regulation of C. elegans life-span by insulin-like signaling in the nervous system. Science 290:147-150.

Zhao B, Khare P, Feldman L, Dent JA (2003) Reversal frequency in Caenorhabditis elegans represents an integrated response to the state of the animal and its environment. J Neurosci 23:5319-5328. 